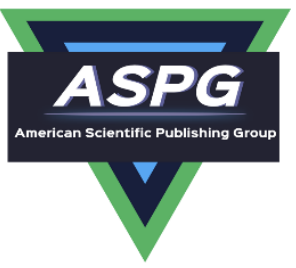

\title{
Integration of Cultural Digital form and Material Carrier form of Traditional Handicraft Intangible Cultural Heritage
}

\author{
Saeed M. Aljaberi ${ }^{1,2}$, Ali Saadon Al-Ogaili ${ }^{3, *}$ \\ ${ }^{1}$ Computer Science, Staffordshire University, UK \\ ${ }^{2}$ Artificial Intelligence department, Dubai Police, Dubai, UAE \\ ${ }^{3}$ Institute of Power Engineering (IPE), Universiti Tenaga Nasional, Kajang, Selangor, Malaysia \\ Emails: eljabri@live.com, alinasrieh.edu@gmail.com
}

\begin{abstract}
Intangible cultural heritage is the continuous progress of human society. Intangible cultural heritage refers to various traditional cultural expressions that exist in intangible form and are closely related to the lives of the people and inherited from generation to generation. Intangible cultural heritage is a human-oriented living cultural heritage. It emphasizes human-centric skills, experience, and spirit, and is characterized by living changes. What stands out is the intangible attribute, and more emphasis on the quality that does not depend on the material form. The biggest feature of intangible cultural heritage is that it is not divorced from the special life and production methods of the nation, and it is the "living of the nation's personality and national aesthetic habits. "Appears. It exists on the basis of human beings, using voice, image and skills as means of expression, and passing from word to mouth as a cultural chain to continue. It is the most vulnerable part of "living" culture and its traditions. Therefore, for the process of inheriting intangible cultural heritage, the inheritance of people is particularly important. The traditional handicraft intangible cultural heritage is one of the best. However, with the rapid development of society, the living environment of intangible cultural heritage has changed, and the intangible cultural heritage of traditional handicraft industry is rapidly declining or even disappearing. In order to protect traditional handicraft intangible cultural heritage, this article studies the influence of the integration of traditional handcrafted intangible cultural heritage with the form of material carrier, reading and analyzing a large number of related documents using the literature survey method, and according to research needs, through the study of the content of the literature In summary, a questionnaire survey method was adopted to investigate traditional handicraft intangible cultural heritage visitors and inheritors. The results of the survey found that visitors' satisfaction with the integration of digital forms and physical carrier forms of intangible cultural heritage projects was nearly $30 \%$ higher than that of unintegrated forms. Inheritors generally believe that integrated research has better publicity and education for traditional handicraft intangible heritage. The merged handmade intangible cultural heritage items are easy to store, retrieve and query, and at the same time help to preserve the related traditional handmade intangible cultural heritage items safely and for a long time, making the traditional handmade intangible cultural heritage items widely spread and shared around the world.
\end{abstract}

Key words: Intangible Cultural Heritage, Cultural digitization, Traditional, Non-genetic inheritor, handmade intangible heritage

\section{Introduction}

Our country's traditional handicrafts, as the material cultural heritage and spiritual cultural relics of the folk life culture created, enjoyed and passed on by the general public, have an important position in China's history and culture. The development of modern society has caused changes in the living environment of intangible cultural heritage, and it is difficult to adapt to modern living conditions, which has caused it to encounter problems that have 
never been encountered in the process of inheritance. It is difficult to rely solely on the efforts of the inheritors of intangible cultural heritage. Solve such problems [1-3]. Now in the digital age, digital technology with many advantages such as convenient and concise operation, easy to be accepted by the public, reproducibility and storage, has become a powerful measure to save and help pass on some precarious intangible cultural heritage projects, so digital technology The role in the link of intangible cultural heritage inheritance is undeniable, and it must be applied reasonably [4].

The digital technology of modern society has changed before you have to go to the museum to see the fine collections, and can make short-term exhibitions long-term preservation [5-7]. The current digital protection of intangible cultural heritage mainly uses video recording to find a more complete record. At the same time, digital protection is also being carried out across the country, and databases have been established [8-9].

With the improvement of relevant technical levels, cultural protection workers in European and American countries have begun to use digital technology and information technology to explore the restoration of intangible cultural heritage, seek the reproduction of their overall original appearance, and promote the technical means to spread in the direction of the Internet. Rapid development.

In 2011, Google launched the "Art Project" through mutual assistance and collaboration with exhibition halls and art institutions around the world. By making full use of its superior technology "Street View", it created a yearround online museum. As of April 2018 It has hosted many top exhibition halls, including the Louvre in Paris, the Palace Museum of China, and the National Gallery of Britain. As long as they log on to its website, people can remotely watch high-definition art works, experience 360-degree group photo videos, and browse world-famous At the same time, the website will periodically update the exhibition halls and works [10-13]. The reasonable application of technical means can not only make the original state of intangible heritage be reproduced in the cultural space, but also meet the needs of many audiences, so that intangible cultural heritage can be better inherited and promoted [14-16].

Liang Lin and Gao Han discussed the dilemma of the inheritance of traditional handicrafts, and put forward views and solutions to the inheritance of traditional handicrafts, that is, to change the concept of inheritance and improve the inheritance environment [17-22]; Fang Lili used Jingdezhen ceramics as a sample to discuss the traditional handicrafts The possibilities of diverse development in contemporary society[22]; Xu Lingmin proposes to combine traditional handicrafts with craftsmanship, carry forward the advantages of handicrafts, and promote intangible cultural heritage[23-25]; Liu Qin explores the protection and inheritance methods of traditional handicrafts in China, and studies How to promote traditional handicrafts is more acceptable to the audience[26]; Zhu Tengfang discussed the current spread of traditional handicrafts and researched the innovation of traditional handicrafts[27].

In general, the current status of domestic research on digital inheritance of cultural heritage is focused on project construction and technical realization. Humanities and social science theoretical researchers have not paid enough attention to interdisciplinary research. Relatively speaking, foreign research on digital protection of cultural heritage More advanced, in terms of theoretical research, researchers have conducted theoretical explorations on the digitalization of cultural heritage from the aspects of media and cultural criticism [28-29].

\section{Intangible Cultural Heritage Digitization and CarrierIntegration Method}

\subsection{Intangible Cultural Heritage}

Intangible cultural heritage inheritance refers to the various practices, performances and expressions, knowledge systems, skills and related tools, objects and crafts, and traditional culture that are inherited by various groups, groups, and sometimes regarded as their intangible cultural heritage. Place [30]. At present, intangible cultural heritage is classified through the "seven points method". The biggest features of this method are:

(1) While including all intangible cultural heritage content, it is compatible with the classification system of other countries, so as to avoid obstacles in international communication and provide a good platform for international information sharing.

(2) This classification method has the equivalence relationship of the classifications in the same level, avoiding the overlapping problems in the previous classification methods, and ensuring the uniqueness of the project classification.

(3) The number of various projects under this classification method is relatively balanced, so as to ensure the standardization and operability of the classification.

(4) The unified classification standard avoids the randomness caused by the different classification standards when entering the file. 
"Seven points method" specific classification

1) Folk literary heritage refers to all kinds of lively folk oral literary works produced and inherited in the development of human society. Since these projects are mainly spread among the people, the way of inheritance is also by people's word of mouth. Such works include: folk prose literature, such as jokes, myths, fables, etc., as well as folk literature in rhyme styles such as ballads and proverbs [31]. Human beings use folk literature as one of the important channels to record and tell their own history, and at the same time, there is no doubt about the role of their own literary talents.

2) Performing arts heritage refers to various forms of live performance that are produced and inherited in the development of human society. During the performance, the inner thoughts of the performers are transmitted through skills, so that the audience can accept [32]. The specific manifestations of this type of heritage include rap, drama, song and dance, music, sports, acrobatics, and entertainment.

3) Traditional arts and crafts heritage appeared in the process of human development. The skills and skills handed down with the reproduction and continuous development of mankind, which include a wide range of content, such as traditional painting, engraving, weaving, embroidering, printing, dyeing, Color tie, sculpture, ceramic making, etc. belong to our traditional arts and crafts[33]. The characteristics of these traditional craftsmanship have the following two aspects. First, professionalism. These inheritors are all craftsmen and entertainers with strong professional skills, and maintain the professional characteristics of products; second, aesthetics, traditional aesthetics Expressed through professional skills. The inheritance of traditional aesthetics and skills is the main value of this type of heritage [34].

4) Traditional production knowledge heritage appears in the process of human development. As humans multiply and continue to develop, they have regional specific production knowledge experience, such as agricultural production, animal husbandry production, fishery production, hunting, etc. Knowledge [35]. Its main value lies in the inheritance of the national production experience and knowledge and the sustainable development of all aspects of society.

5) The heritage of traditional life knowledge appears in the process of human development. As humans multiply and are continuously developed, the knowledge and experience used in life are passed down, including traditional food, clothing, architecture, transportation, and Chinese medicine. content. This type of heritage includes all kinds of knowledge and skills related to life, and its value is mainly reflected in the cognition of national life knowledge and practice.

6) In the process of human development, traditional ritual heritages appear as living ritual heritages with high cognitive historical, artistic, social and cultural values handed down as humans multiply and are continuously developed. In terms of specific use, it can be divided into two types: human-human rituals and human-natural rituals. The relationship between people mainly includes sacrifices to ancestors, sacrifices to the ancestors of the industry, and various life rituals; while the sacrifices to gods, rain gods, etc. belong to the ritual activities of the relationship between man and nature [36]. This kind of activity has considerable stability, and has a high value of existence in human's cognition of history and culture and the processing of human relations.

7) In the process of human development, traditional festival heritage has lively festivals that have been passed down along with the multiplication and continuous development of human beings, which have cultural, social and artistic value. This type of heritage is mainly classified according to the scope of application, including the National Spring Festival, Mid-Autumn Festival, etc., as well as the Songkran Festival and Torch Festival with the characteristics of ethnic regions. Each festival is an integration of various excellent traditional cultures, reflecting the relatively excellent traditional heritage within the scope of [37]. Such heritage preserves national traditions and strengthens national cohesion.

\subsection{Traditional Handmade Intangible Cultural Heritage Projects}

Traditional hand-made intangible cultural heritage projects are the skills and skills handed down with the reproduction and continuous development of human beings in the process of human development. They include a wide range of content, such as traditional painting, engraving, weaving, embroidery, embroidering, printing, and Color tie, sculpture, ceramic making, etc. are all our traditional crafts[38].

Traditional handmade intangible cultural heritage features:

(1) Specific ethnicity. The development history of different nationalities has their own characteristics, and they show different cultural characteristics according to their different living customs, ways of thinking, and behaviors. Specifically, it is verbal expression in national language, deduction with unique performance style and its own ceremonial ceremonies, to show people's understanding of the world and nature, and multiple channels to show its history and heritage. 
(2) Liveness, the characteristics of each nation are different from other nations, and these characteristics can be expressed by the nation's unique way of thinking, language, and behavior. Use unique language, unique performance styles and methods to express the knowledge of nature and the universe. It contains historical and heritage.

(3) Mainly adopt the inheritance path of oral teaching. What is more prominent in the inheritance of intangible cultural heritage is that it uses the oral narration of the previous generation of inheritors to demonstrate the cultivation of the next generation of inheritors, which is collective and oral. Oral is mainly embodied in skills that use oral as a form of performance, such as social etiquette, oral legends, and folk's cognition of the universe and nature; collectiveness is mainly embodied in the skills inherited in the form of group performances, which are usually performed by groups or Multiple natural persons participate in the development process and continuously incorporate the thinking and improvement of the inheritors, so that the art form is continuously enriched..

\subsection{Non-genetic Inheritor}

Over the years, the understanding of what is passed down by the inheritor is not complete. The current more unified understanding is to pass on the memory through traditional methods, so that the memory can be preserved and developed. Although this method of inheritance will not disappear, the following three problems will arise: first, the inheritance process pays too much attention to traditional forms, and the next generation of inheritors loses innovation, resulting in stagnant project development; second, inheritance training In the process, the culture and history contained in the multi-techniques were not described enough, which caused many skills to have their outer shells, lack of understanding of the inside, and the works are stylish but not godless; third, the inheritors are eager to see results under the influence of modern fast-paced life, Eager for quick success, lack of respect for skills, lack of craftsmanship, such traditional skills are difficult to develop further.

No one inherits traditional handcrafts. It takes about 3 to 5 years for a traditional craftsmanship to get a good grasp of its essence. The expenditure and income during the course of study are not proportional, and even if it is learned, the current development prospects of traditional craftsmanship are not Not optimistic, the income can not even meet the basic needs of life [39]. For this traditional handicraft industry with high investment and low return, most people are unwilling to engage in it.

The production of traditional handicrafts is mainly done by people. Even if you learn the same craft, it will be different due to various human factors such as everyone's comprehension and experience. People occupy the main part in the production process. status. Traditional handicraftsmen must use the best materials and spend a lot of time and energy in order to better present their products, which intensifies the production cycle of products and increases costs and prices. The method of industrialized mass production is through the collective operation of the machine, the production speed is fast, the cycle is short, and generally does not care too much about the problems of raw materials and processing, so the cost is lower, the price is cheap, and there is no need to worry about product damage, because The same substitute can be found at any time. Obviously, this mode of production is more suitable for the needs of modern society. my country has also made efforts to protect inheritors

(1) After Kunqu Opera successfully entered the World Intangible Heritage List at the beginning of the 21st century, with the active efforts of relevant government departments, the inheritance mechanism has achieved initial results. At the same time, there is also protection work, especially the protection of representative inheritors and inheritance systems, and certain achievements have been made.

(2) The government, as the main body of protection, actively promotes the protection of inheritors and comprehensively promotes the protection of other aspects. The first is to make the confirmation of the declared successor more standardized through various rules and regulations, while making the responsibilities and obligations of all parties more clear. Make protection work rules to follow [39]. The second is to use a variety of ways and methods to understand the actual situation of different inheritors. Use a variety of digital recording methods such as photos, videos, etc. to record intangible cultural heritage items as comprehensively as possible. Through this work, a large number of precious materials have been obtained and archived. The third is to actively cooperate with the promotion activities launched by the inheritors to improve the promotion effect.

(3) Train a new generation of inheritors in multiple ways. Although the protection work has made great progress after more than ten years under the leadership and promotion of the government, an effective inheritance mechanism has also been initially established, and the inheritance status of some projects has been improved, and the earlier inheritors have become representative inheritance. People or outstanding talents shoulder the important task of cultivating new talents.

2.4 Cultural Digitization

Cultural digitization is the use of a series of digital technologies to transform cultural heritage into a digital

DOI: $10.5281 /$ zenodo.5213115

Received: March 06, 2021 Accepted: June 19, 2021 
form, interpret it from a new perspective, and use it in a new way. With the continuous development of science and technology, especially the development of electronic digital technology, a solid technical foundation has been provided for the digital protection of cultural heritage. Digital cultural heritage technology will digitally process and store text, pictures, audio-visual information and three-dimensional data related to cultural heritage to realize query, management, copy and reuse. It is also possible to further establish digital cultural heritage museums and exhibition halls, which are not restricted by time and space, and display cultural relics and historical sites clearly through the network and computers, serving the protection, development and utilization of cultural heritage [27].

The database is "a warehouse for storing and managing data according to the data structure". The electronic computer system community generally believes that a database is a "reasonable and effective storage of interconnected data collections on computer system storage devices. These data are organized and stored by a certain data model, and the data can be used in the best way, at least multiple times by users. Sharing and applicable." The traditional handicraft intangible cultural heritage database is a collection of links to certain categories of sports intangible cultural heritage materials through regulation, collection and storage, and storage in a certain format for easy access and use

Digitalization of intangible cultural heritage makes intangible cultural heritage more intuitive, true, comprehensive and multi-angled compared with traditional protection methods such as master-disciple transmission, ordinary text, and pictures. It also has a simple and easy-to-use copy and storage form of data preservation. Intangible cultural heritage has the advantages of long time, high safety factor, convenient and quick dissemination, etc., and fully retains the authenticity and integrity of the content of intangible cultural heritage. Therefore, digital technology has become an important carrier for recording, storing, displaying and disseminating intangible cultural heritage.

\section{Experimental Research on the Fusion of Cultural Digitization and Material Carrier}

\subsection{Research Object}

This research takes the digitization of traditional handicraft intangible cultural heritage, and takes empirical research as the main body to obtain the research foundation. Based on the empirical research, it proposes ideas for the protection of traditional handicraft intangible cultural heritage. A total of 50 people were selected to visit traditional handicraft intangible cultural heritage, 50 people were digitized and integrated with carriers, a total of 100 people; 10 people were non-genetic inheritors.

\subsection{Data Sources}

The data in this article mainly come from the statistics of traditional handicraft intangible culture in various regions, the China Intangible Heritage Protection Association, the National Bureau of Statistics and the comprehensive statistical information management platform.

\subsection{Experimental Design of Traditional Manual Methods}

1) Literature research method: mainly refers to the formation of a scientific understanding of research facts by collecting, sorting, summarizing, and analyzing existing literature. By consulting materials in related research fields, including: geographic, humanistic and cultural documents of the region; types and historical records of domestic traditional handicrafts; research documents on domestic and foreign academic journals and information on websites; how foreign countries conduct intangible cultural heritage of traditional handicrafts Policies, measures and practical cases for better protection; using this as the theoretical basis, and at the same time refer to domestic literature on productive protection, as well as cases of how traditional domestic and foreign cultures are combined with cultural and creative industries to form research ideas for the subject.

2) In terms of experimental models, this paper uses GIS spatial analysis technology to conduct geographic spatial analysis of traditional artisanal intangible cultural heritage in different regions, and uses spatial measurement to study the spatial distribution of traditional artisanal intangible cultural heritage in different regions and its formation reasons. Established a spatial autoregressive model (Equation 1) and a spatial error model (Equation 2)

$$
\begin{array}{r}
\Delta=\rho W y+\mathrm{X} \beta+\omega \\
\Delta=\mathrm{X} \beta+\omega, \quad \omega=\lambda W \omega+v \quad(2)
\end{array}
$$

3) Questionnaire survey method. This study is based on the existing research results and adopts the existing model to design the scale. Based on the opinions and suggestions of experts and professors, the researchers select, test and modify the questions and options, and finally form the questionnaire Questionnaire. The questionnaire survey was distributed to two groups, one group to visit traditional handicraft intangible cultural heritage, and one group to visit the digital and carrier morphological integration of intangible cultural heritage. There were 50 people

DOI: $10.5281 /$ zenodo.5213115

Received: March 06, 2021 Accepted: June 19, 2021 
in each group, totaling 100 visitors to understand their visits and the traditional handicrafts The interest level of the legacy, the mastery of the situation, etc.

4) Statistical method of several cases: Use SPSS statistical software to process the relevant data of the valid questionnaire in this experiment, and comprehensively summarize and analyze the relevant statistical results.

\section{Fusion Research Experiment Analysis}

\subsection{Changes in the Number of Chinese Traditional Handmade Intangible Cultural Heritage}

According to relevant information, as of 2018, my country has included 41 items on the UNESCO Intangible Cultural Heritage List, among which traditional handicrafts include shadow puppets, paper-cutting, embroidery, New Year pictures, and puppets. There are 334 kinds of municipal non-heritage in China. However, according to research findings, from 2013 to 2018, due to lack of inheritors and other reasons, a variety of traditional handicrafts were not lost, as shown in Table 1 and Figure 1:

Table1. Intangible Cultural Heritage

\begin{tabular}{|c|c|c|c|}
\hline 4 & Quantity & Intangible cultural heritage & $\begin{array}{c}\text { Quantity of traditional } \\
\text { handmade intangible cultural } \\
\text { heritage }\end{array}$ \\
\hline \multirow{6}{*}{ 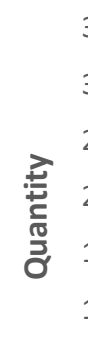 } & 2013 & 316 & 63 \\
\hline & 2014 & 319 & 59 \\
\hline & 2015 & 323 & 57 \\
\hline & 2016 & 327 & 55 \\
\hline & 2017 & 331 & 49 \\
\hline & 2018 & 334 & 43 \\
\hline
\end{tabular}

Figure 1.Intangible cultural heritage quantity and loss change chart

\subsection{Investigation and Analysis of Intangible Cultural Heritage}

Among them, those who integrate intangible cultural heritage digitization and carrier morphology are generally considered to be interesting, practical and efficient in learning; those who participate in traditional intangible cultural heritage reflect more boring, no interest in learning, and no understanding.

Table2. Response statistics

\begin{tabular}{|c|c|c|}
\hline & Experience group & Reference group \\
\hline Interesting & $56.66 \%$ & $13.33 \%$ \\
\hline Good & $23.33 \%$ & $20.00 \%$ \\
\hline General & $11.66 \%$ & $31.66 \%$ \\
\hline Uninteresting & $5.00 \%$ & $16.66 \%$ \\
\hline Boring & $3.33 \%$ & $18.33 \%$ \\
\hline
\end{tabular}




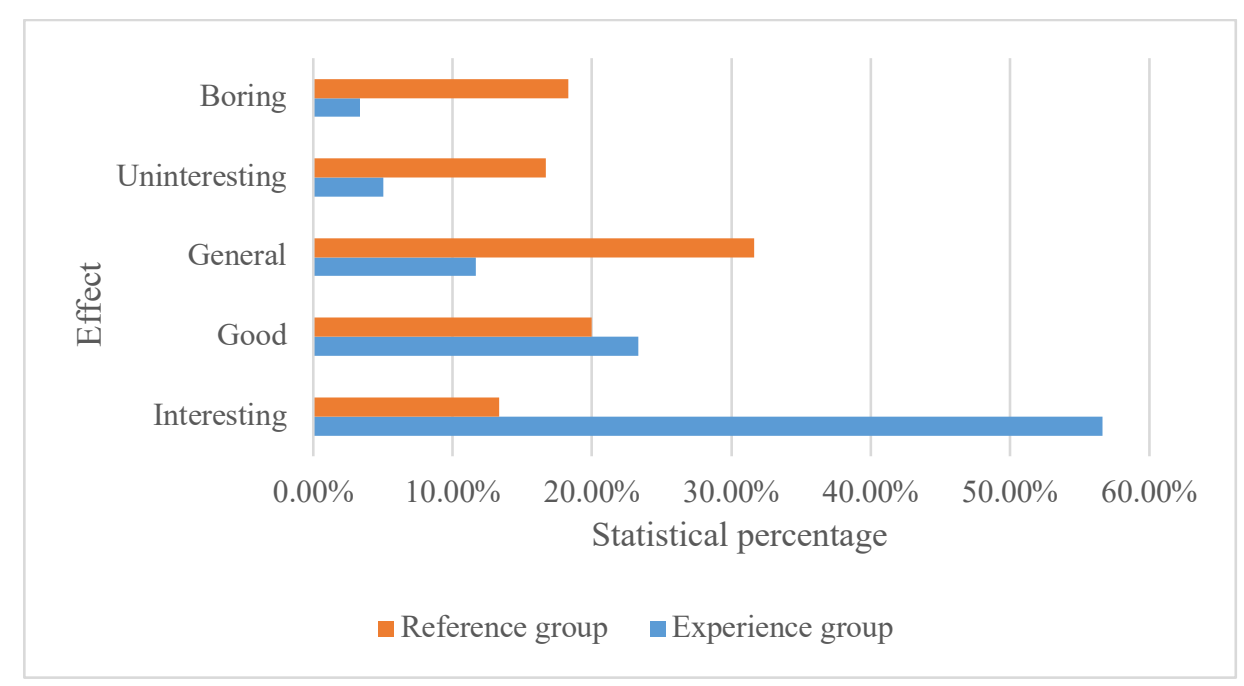

Figure2.Comparison of grouping effect

As shown in Table 2 and Figure 2, the integration group thinks it is very interesting, accounting for $56.66 \%$, which is higher than the traditional $13.33 \%$; the traditional group thinks it is very boring, accounting for $18.33 \%$, which is higher than the integration group' s 3.33\%; the integration group is not interested in courses accounting for $16.66 \%$. The traditional group is $5.00 \%$; the traditional group who thinks very general accounted for $31.66 \%$, and the fusion group was 11.66; the two groups who thought the course was better accounted for a small gap, the fusion group was $23.33 \%$, and the traditional group was $20.00 \%$. From the results, it can be seen that the integration of digital and carrier morphology of intangible cultural heritage can better attract people and have a better dissemination effect on traditional manual intangible cultural heritage.

\subsection{Survey of Education Level of Intangible Cultural Heritage}

This paper investigates the education level of the 20 inheritors who participated in the scoring. The results are shown in Figure 3. Among the 20 inheritors participating in the survey, only 5 have university education, and the rest have lower education levels. the University.

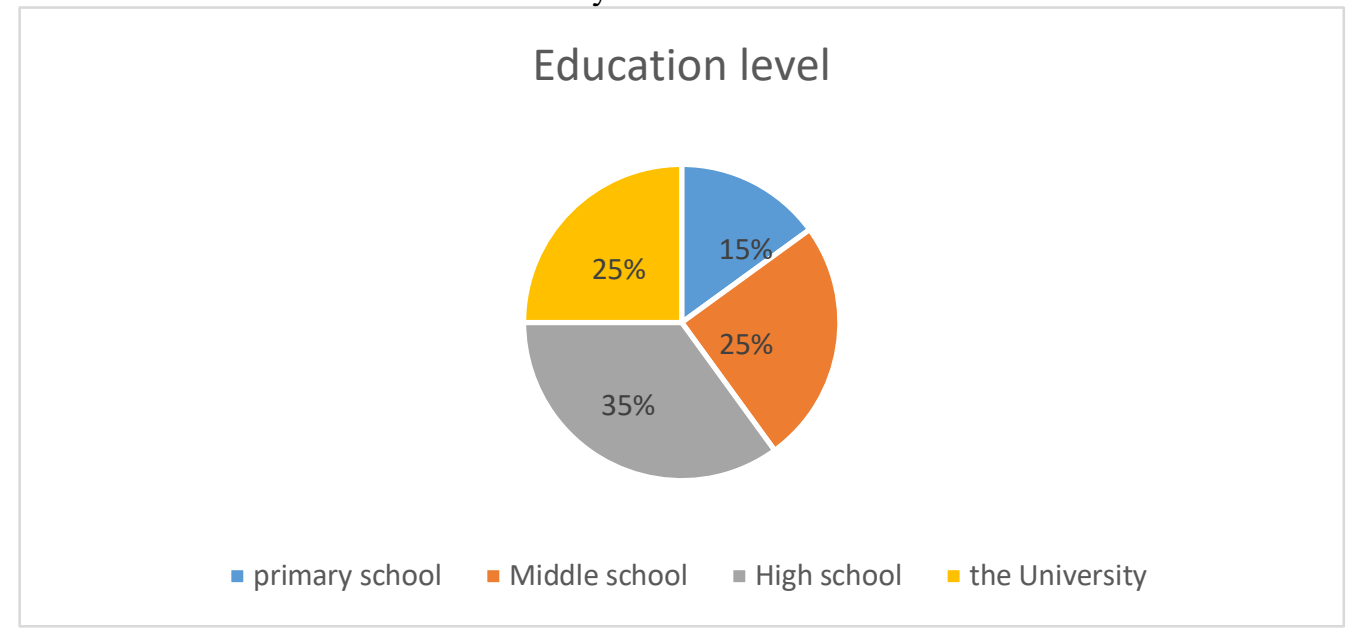

Figure3.Education level of inheritor

The quality of the inheritors directly affects the inheritance skills. At present, the traditional handicrafts in my country are mainly passed on from the master to the apprentice. The traditional handicrafts continue to be taught by oral and heart. Therefore, most inheritors only have relatively good skills in this field. Strong practical ability, but not very familiar with related theories. Nowadays, the low cultural level of the inheritor has become a restrictive factor of non-genetic inheritance, which directly affects the in-depth research and inheritance promotion of the project. In addition, in the work of cultivating new generations of inheritors, some parents are affected by the social environment and believe that their children should enter the social emerging industries after receiving higher education. It also reduces the number of young talents flowing to the inheritance team to some extent. 


\subsection{Inheritor's Evaluation of Integration}

This article conducts a demonstration of the integration of traditional handicrafts with cultural digitization and carrier form through the investigation of non-genetic inheritors, and allows the inheritors to score and evaluate them

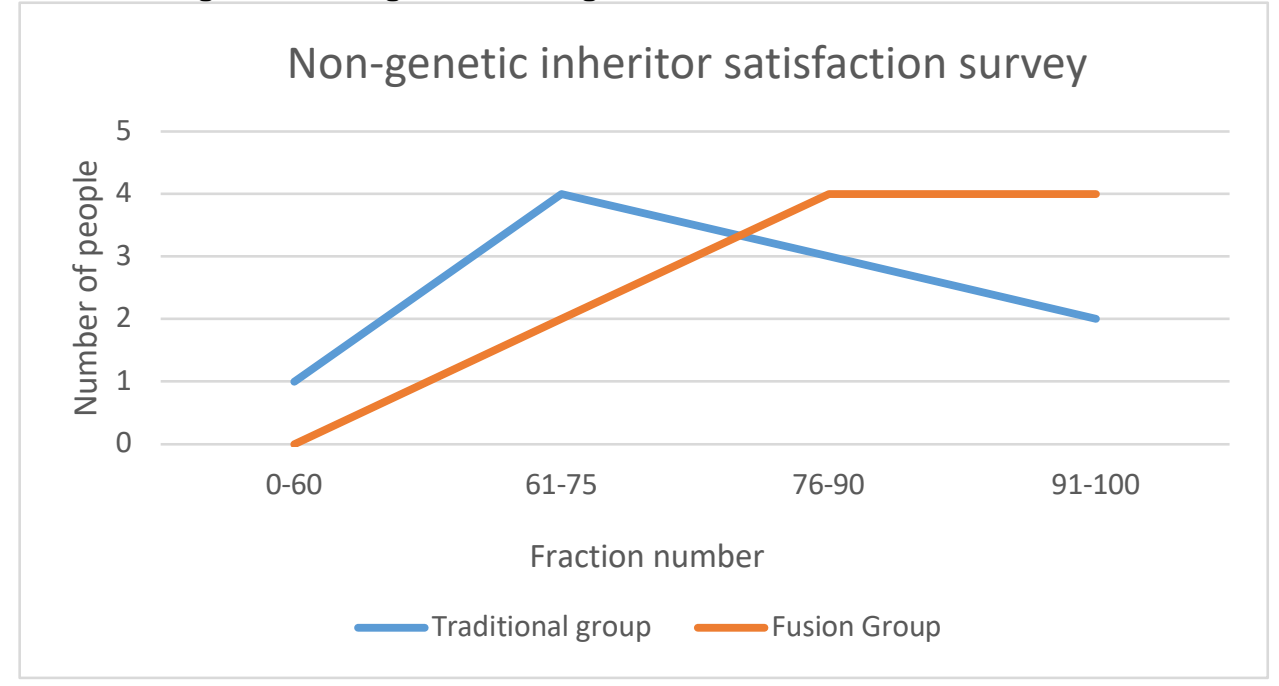

Figure4.Inheritor scoring situation

As shown in Figure 4, most of the fusion group scored an excellent score of 76 points or more, a small number of people scored a good score of 61 to 75 points, and no one gave a failing score; the traditional group scored most of them Good grades, fewer excellent grades, and even one person scored a failing score. The results of the two subgroups fully show that the integration of digital and morphological carrier of traditional handmade intangible cultural heritage is easier for inheritors to accept, which is conducive to the inheritance of traditional handmade intangible cultural heritage.

\section{Conclusions}

The traditional handicraft intangible cultural heritage is precious, and the cultural value it contains is extremely high, which is very important to the cultural security of the nation and the development of the nation's cultural bloodline. Effective protection and rational use of intangible cultural heritage in our country are very important for social development at this stage.

Today, digitization has increasingly become the development trend of global intangible cultural undertakings. To integrate the digitization of traditional hand-made intangible cultural heritage with the carrier form, on the one hand, it is necessary to strengthen the awareness of protection of traditional hand-made intangible cultural heritage; on the other hand, it is necessary to make full use of the advanced technology of cultural digitization to preserve the resource information of traditional hand-made intangible cultural heritage . At present, many traditional skills are on the verge of extinction, and a large number of precious artifacts and materials with historical and traditional cultural value have been destroyed. Take scientific measures to protect and protect the intangible cultural heritage of traditional handicrafts left by the traditional culture of mankind. Inheritance is of great significance to the sustainable development of human society.

The rapid development of digital technology level has brought unprecedented opportunities for the development and protection of my country's cultural heritage. It is promoting the full realization of cultural heritage sharing and inheritance in an unprecedented manner and speed. Combining the digitalization of traditional handmade intangible cultural heritage with the carrier form, users can inquire and view materials in different regions according to their own needs, which is suitable for the dissemination of basic knowledge for traditional handmade cultural heritage lovers, and is also suitable for traditional handmade intangible cultural heritage. The tangible cultural heritage managers can more conveniently check the basic contents of the traditional handmade intangible cultural heritage items.

\section{References}


[1] Fang Lili. On the Inheritance of "Intangible Heritage" and the Diversified Development of Contemporary Society: Taking Jingdezhen Traditional Handicraft Revival as an Example[J]. National Art, 2015,003(1):71-83.

[2] K. Yu, Z. Guo, Y. Shen, W. Wang, J. C. Lin, T. Sato, "Secure Artificial Intelligence of Things for Implicit Group Recommendations", IEEE Internet of Things Journal, 2021

[3] H. Li, K. Yu, B. Liu, C. Feng, Z. Qin and G. Srivastava, "An Efficient Ciphertext-Policy Weighted Attribute-Based Encryption for the Internet of Health Things," IEEE Journal of Biomedical and Health Informatics, 2021

[4] Xiao Wei. On the "Richness of Authenticity"_ _ On the value of traditional arts and crafts, hand craftsmanship and intangible cultural heritage inheritance[J]. Journal of Henan University of Technology (Social Science Edition), 2015, v.11;No.44 (04):106-109+135.

[5] Liang Lin, Gao Han. Inheritance of Intangible Cultural Heritage Schools of Traditional Handicraft Skills[J]. Vocational Education Forum, 2015, 032(010):81-84.

[6] K. Yu, L. Tan, S. Mumtaz, S. Al-Rubaye, A. Al-Dulaimi, A. K. Bashir, F. A. Khan, "Securing Critical Infrastructures: Deep Learning-based Threat Detection in the IIoT", IEEE Communications Magazine, 2021.

[7] L. Zhen, A. K. Bashir, K. Yu, Y. D. Al-Otaibi, C. H. Foh, and P. Xiao, "Energy-Efficient Random Access for LEO Satellite-Assisted 6G Internet of Remote Things", IEEE Internet of Things Journal

[8] Liu Xiao, Xu Zhenzhen. Inheritance of Intangible Heritage Traditional Handicraft Skills Based on Modern Apprenticeship: Inherent Mechanism and Functional Value[J]. China Vocational and Technical Education, 2017,000(11):11-17.

[9] Liu Qin. "How to Look" and "What to Exhibit"__ Talking about the narrative of "Intangible Heritage" traditional handicraft exhibition[J]. Art Observation, 2017,01(1):11-17.

[10] L. Zhen, Y. Zhang, K. Yu, N. Kumar, A. Barnawi and Y. Xie, "Early Collision Detection for Massive Random Access in Satellite-Based Internet of Things," IEEE Transactions on Vehicular Technology, vol. 70, no. 5, pp. 5184-5189, May 2021

[11] L. Tan, K. Yu, N. Shi, C. Yang, W. Wei and H. Lu, "Towards Secure and Privacy-Preserving Data Sharing for COVID19 Medical Records: A Blockchain-Empowered Approach," IEEE Transactions on Network Science and Engineering

[12] Chi Xiaoli, Wang Huilei. Analyzing the digital dissemination of intangible cultural heritage of traditional handicrafts in Xiangxi[J]. Literary and Art Life-Wenhai Yiyuan, 2018, 031(006):140-141.

[13] Zhu Tengfang. Research on the Innovation of Traditional Handicraft Design in Intangible Cultural Heritage[D]. 2019,031(03):14-16.

[14] K. Yu, L. Tan, L. Lin, X. Cheng, Z. Yi and T. Sato, "Deep-Learning-Empowered Breast Cancer Auxiliary Diagnosis for 5GB Remote E-Health," IEEE Wireless Communications, vol. 28, no. 3, pp. 54-61, June 2021

[15] L. Tan, K. Yu, F. Ming, X. Cheng, G. Srivastava, "Secure and Resilient Artificial Intelligence of Things: a HoneyNet Approach for Threat Detection and Situational Awareness", IEEE Consumer Electronics Magazine, 2021

[16] Shao Mingli. Research on the Tourism Development Model of Intangible Cultural Heritage of Traditional Handicrafts in Chuzhou City[J]. Journal of Jixi University, 2016, 16(10):75-78.

[17] Sun Fengmin, Sun Hongyan. The modern inheritance of intangible cultural heritage of traditional handicraftsBased on the perspective of modern apprenticeship[J]. Vocational and Technical Education, 2017, 38(013):39-43.

[18] Z. Guo, K. Yu, Y. Li, G. Srivastava, and J. C. -W. Lin, "Deep Learning-Embedded Social Internet of Things for Ambiguity-Aware Social Recommendations", IEEE Transactions on Network Science and Engineering.

[19] F. Wang, J. Fu, Y. Zhu. Coarse and Fine Data Fusion of Absolute Round Inductosyn[J]. Chinese Journal of Sensors \& Actuators, 2018, 31(2):213-217.

[20] L. Tan, K. Yu, A. K. Bashir, X. Cheng, F. Ming, L. Zhao, X. Zhou, "Towards Real-time and Efficient Cardiovascular Monitoring for COVID-19 Patients by 5G-Enabled Wearable Medical Devices: A Deep Learning Approach”, Neural Computing and Applications, 2021

[21] Z. Guo, K. Yu, A. Jolfaei, A. K. Bashir, A. O. Almagrabi, and N. Kumar, "A Fuzzy Detection System for Rumors through Explainable Adaptive Learning", IEEE Transactions on Fuzzy Systems

[22] Tian Zhuoming. Breakthrough and Innovation of Traditional Handicrafts in the Context of Intangible HeritageTaking the exploration of Jingle paper-cut and light-shadow paper sculpture as examples[J]. Hunan Packaging, 2017, 26(004):39-42.

[23] Liu Hongping, Ma Yanan, Liu Yao. The Tourism Development Conception of Intangible Cultural Heritage of Traditional Handicrafts in Qinhuangdao[J]. Journal of Chifeng University (Nature Edition), 2015, 002(010):59-61. 
[24] L. Tan, N. Shi, K. Yu, M. Aloqaily, Y. Jararweh, "A Blockchain-Empowered Access Control Framework for Smart Devices in Green Internet of Things", ACM Transactions on Internet Technology, vol. 21, no. 3, pp. 1-20, 2021

[25] Z. Guo, A. K. Bashir, K. Yu, J. C. Lin, Y. Shen, "Graph Embedding-based Intelligent Industrial Decision for Complex Sewage Treatment Processes", International Journal of Intelligent Systems, 2021

[26] Hu Jiyan, Du Yumin. Research on the Creative Industrialization of Intangible Cultural Heritage of Traditional Handicrafts from the Perspective of Cultural Ecology*--Taking Anhui Jieshou Painted Pottery as an Example[J]. Journal of Guangxi Normal University (Philosophy and Social Sciences Edition), 2015, 023( 006): 12-16.

[27] Cheng Yao, Zhang Shencheng. The Revival of Traditional Handicrafts from the Perspective of Intangible Cultural Heritage Protection[J]. Journal of Changchun Normal University, 2016, 035(010):195-197.

[28] Gao Yi. An Analysis of the Integration Mode of Intangible Heritage Traditional Handicrafts and Tourism Cultural and Creative Industries_ A Case Study of Fuzhou Boron Lacquer Decoration Techniques[J]. Yiyuan, 2016, 031(006):84-86.

[29] Zhang Hongmei. Re-discussion on the integration of handicraft intangible cultural heritage into the teaching of tourism souvenir design in colleges and universities[J]. Design, 2017, 003(001):76-77.

[30] Li Jun, Fu Wei. Research on the Dilemma and Countermeasures of Intangible Cultural Heritage Digital Protection in Guangzhou[J]. Journal of Guangzhou City Vocational College, 2017, 11(002):9-13.

[31] Chen Shanwei. Research on application of digital protection platform for intangible cultural heritage in the western part of Guanzhong[J]. Journal of Baoji University of Arts and Science (Natural Science Edition), 2015, 035(003):40-44+51.

[32] Zhong Lei, Zhou Peng. Analysis on the Digital Protection of Intangible Cultural Heritage under the Multiple Forms of New Media[J]. Packaging Engineering, 2015, 036(010):1-4.

[33] $\mathrm{Hu}$ Yuanhui. Thinking and inheritance education of digital protection of intangible cultural heritage in the context of new media: A case study of musical intangible cultural heritage in Guangdong Province[J]. Music Education and Creation, 2019, 015(007):18-22.

[34] Yang Jubao. Research on the Necessity and Application of Intangible Heritage Digital Protection and Inheritance[J]. Mingri, 2019,031(40):35-36.

[35] Quan Xi. "Internet+": Constructing a New Scene for Digital Inheritance of Intangible Cultural Heritage[J]. Journal of Northwest University for Nationalities: Philosophy and Social Science Edition, 2017,017(06):181-184.

[36] Jin Yinqin. Status Quo and Thinking of Digital Protection of Intangible Cultural Heritage-Taking Zhejiang Province as an Example[J]. Science and Technology Information Development and Economy, 2015,04(07):144-146.

[37] Zhai Shanshan, Xu Xin, Sun Yawei, et al. Research on the protection of intangible cultural heritage digital archiving from the perspective of memory engineering[J]. Library Science, 2017, 010(004):47-53.

[38] Xu Xin. Research on Intangible Cultural Heritage Digitization Oriented to Inheritance and Dissemination[J]. Shanghai University Library and Information Work Research, 2018, v.28; No.110(02):31-32.

[39] Ge Fang. Research on Digital Communication of Folklore Intangible Cultural Heritage from the Perspective of Digital Media_-Taking Huangmei Puppet Show as an Example[J]. Journal of Tonghua Teachers College, 2019, 040(005):813. 